\title{
Competitive Intelligence Location in Small and Medium-Sized Enterprises
}

\author{
Tshilidzi Eric Nenzhelele
}

\author{
Senior Lecturer, University of South Africa
}

nenzhte@unisa.ac.za

\section{Doi:10.5901/mjss.2014.v5n23p608}

\begin{abstract}
The business world is dynamic and unpredictable. To adapt and survive in this kind of business environment, enterprises must implement competitive intelligence. Competitive intelligence produces actionable intelligence that provides help in decisionmaking and provides competitive advantage to enterprises. In order for competitive intelligence to be effective, it must be correctly located within the enterprise. There has been disagreement on where competitive intelligence should be located within the enterprise. Moreover, little research has been conducted on where within the enterprise to place competitive intelligence. Also, research conducted with regard to competitive intelligence location has been on larger enterprises than small ones. Therefore, the purpose of this research is to establish the location of competitive intelligence within small and mediumsized enterprises.
\end{abstract}

Keywords: Competitive Intelligence, Competitive Intelligence Location, Small and Medium-sized Enterprises, Decision-making, Competitive Advantage

\section{Introduction}

The business world is dynamic and unpredictable (Raynor, 2007). To adapt and survive in this kind of business environment, enterprises must implement competitive intelligence (CI) (Adidam, Banerjee \& Shukla, 2012). Cl produces actionable intelligence that provides help in decision-making and provides competitive advantage to enterprises (Ponis \& Christou, 2013). Through the help of $\mathrm{Cl}$, enterprises are aware of what their competitors' moves (Onifade, Thiery, Osofisan \& Duffing, 2013). According to Hesford (2008), Cl enhances the performance of enterprises.

In order for competitive intelligence to be effective, it must be correctly located within the enterprise (Adidam, Banerjee \& Shukla, 2012). There has been disagreement on where competitive intelligence should be located within the enterprise. Moreover, little research has been conducted on where within the enterprise to place competitive intelligence (Nasri, 2011). Also, research conducted with regard to competitive intelligence location has been on larger enterprises than small ones (Bartes, 2012). Therefore, the purpose of this research is to establish the location of competitive intelligence within small and medium-sized enterprises.

\section{Competitive Intelligence}

Breese-Vitally (2011) states that with the growth of the global economy; organisations (large and small) are increasingly recognising that $\mathrm{Cl}$ is essential to compete in an industry. According to Deng and Luo (2010), Cl plays an increasingly important role in the strategic management and decision-making of an enterprise. Peltoniemi and Vuori (2008) point out that through $\mathrm{Cl}$, enterprises aim to acquire relevant and accurate knowledge about the actions and plans of competitors on which managers can base their decisions.

$\mathrm{Cl}$ is not an activity that is limited to a few countries or enterprises in certain industries; it is a world-wide phenomenon (Muller, 2007a). Muller (2007) indicates that in order for enterprises to make optimal use of $\mathrm{Cl}$, there should be appropriate enterprise awareness of $\mathrm{Cl}$. She also says that without proper awareness and attitudes that favour both intelligence and information sharing, it is difficult to develop intelligence within an enterprise. Furthermore, she points out that $\mathrm{Cl}$ is still in a growing phase in South Africa due to (1) a lack of awareness of its benefits and (2) inadequate formal training programmes at a higher education level (Muller, 2007). While $\mathrm{Cl}$ is mostly practiced by larger enterprises in industries such as banking, telecommunications and retail, research reveals that it is not well practiced by small enterprises (Murphy 2006). However, it can be practiced successfully by small and medium-sized enterprises (SMEs) (Murphy, 2006). Wright (2005) states that it is not enough for enterprises to have $\mathrm{Cl}$, they need to implement it in the decision-making process. 
$\mathrm{Cl}$, which is the research construct of this research, requires proper definition. There are numerous definitions for $\mathrm{Cl}$ in contemporary practice and scholarship, and no single definition is likely to be precise and universally accepted (Fleisher \& Wright, 2009; Brody, 2008). Brody (2008) argues that because $\mathrm{Cl}$ is a process that is set in situations that are dynamic and in which the players are moving forward in a constantly changing business environment, the variety of definitions may be a reflection of the process of change. For the purpose of this study, $\mathrm{Cl}$ is defined as "a process or practice that produce actionable intelligence by ethically and legally collecting, processing and analysing information about the external or competitive environment in order to help in decision-making and to provide competitive advantage to the enterprise (Nenzhelele \& Pellissier, 2013)."

$\mathrm{Cl}$ is an amalgam of disciplines. It evolved from economics, marketing, military theory, information science and strategic management (Juhari \& Stephens, 2006). According to Muller (2005a), Cl took root in South Africa in the mid1990s and early 2000s. South African enterprises have been too inward-looking, which has made them vulnerable to unforeseen threats (Adidam, Gajre \& Kejriwal, 2009). While $\mathrm{Cl}$ is a relatively new management tool, it is evolving in complexity and importance to maintain pace with rapid business development (Heppes \& Du Toit, 2009). Since the end of the Cold War, $\mathrm{Cl}$ - once widely used in the military environment - has rapidly infiltrated into business competition (Deng \& Luo, 2010).

Due to intense global competition, enterprises are always looking for ways to gain competitive advantage over their competitors (Hughes, 2005; Muller, 2005b). According to Heppes and Du Toit (2009), an enterprise has a competitive advantage whenever it has an edge over its rivals in attracting customers and defending itself against the competitive forces found in its external environment. Enterprises that are facing greater competition devote greater enterprise support to $\mathrm{Cl}$ in searching for new ways of creating and sustaining a competitive advantage (Hesford, 2008; Heppes \& Du Toit, 2009; Adidam et al. 2009). Cl enhances an enterprise's competitive advantage through a better understanding of the enterprise's external (competitive) environment, leading to improved strategic management and resultant competitive advantage (Muller, 2007; Shih et al. 2008; Trim \& Lee, 2007; Heppes \& Du Toit, 2009).

Pietersen (2006) indicates that $\mathrm{Cl}$ captures the knowledge resources required by management. Moreover, the purpose of $\mathrm{Cl}$ in the enterprise is to support (and lead to) management decisions and actions (Dishman \& Calof, 2008). Thus, $\mathrm{Cl}$ influences decision making and decision making is a possible research variable. Furthermore, $\mathrm{Cl}$ includes monitoring competitors, identifying opportunities and threats in the industry, leading enterprises to simulate their strength and weaknesses, building scenarios and planning counter-attacks (Trim \& Lee, 2008). Efficient $\mathrm{Cl}$ activities can help an enterprise to understand its strengths and weaknesses in relation to its competitors. In this way, an enterprise can anticipate, with some accuracy, the future moves of its competitors (Peltoniemi \& Vuori, 2008). By analysing the capabilities, vulnerabilities, intentions and moves of competitors, $\mathrm{Cl}$ allows an enterprise to anticipate market developments proactively - rather than merely react to them. This in turn enables the enterprise to remain competitive by improving its strategic decisions and performing better than its competitors (Bose, 2008; Shih Liu \& Hsu, 2008; Johns \& Van Doren, 2010; Hesford, 2008). Thus, Cl influences competitiveness, performance and decision making, making these possible research variables. Also, Hughes (2005) mentions that $\mathrm{Cl}$ can help an enterprise to understand how and where to find unique resources and capabilities that can help it to compete more effectively. $\mathrm{Cl}$ therefore also influences resource management and capabilities, making these possible research variables.

$\mathrm{Cl}$ is a strategic tool and aid in decision making (Nasri, 2011; Bourret, 2012; Patterson \& Martzoukou, 2012). According to Bose (2008), $\mathrm{Cl}$ is a vital component of an enterprise's strategic planning and management process. Furthermore, Bose (2008) and Hesford (2008) state that the primary output of $\mathrm{Cl}$ is the ability to make forward-looking decisions. Zha and Chen (2009) argue that $\mathrm{Cl}$ determines the survival of enterprises. Consequently, enterprises are paying attention to $\mathrm{Cl}$ because it supports their needs in terms of gathering, interpreting and disseminating external information (Strauss \& Du Toit, 2010). Thompson and Martin (2005) define strategy as a means to an end, and the end concerns the purpose and objectives of the enterprise. Pearce and Robinson (2005) define the strategic management process as a set of decisions and actions that results in the formulation and implementation of plans designed to achieve an enterprise's objectives. Simon (1997) proposes a three-phased process of decision making: (1) the intelligence phase, (2) the design phase and (3) the choice phase. Sauter and Free (2005) conclude that high-level decision makers are dependent on doing the first of these phases: the intelligence phase.

While $\mathrm{Cl}$ offers an enterprise a lot of benefits, it also presents some challenges. SMEs face a bigger challenge in building and developing an effective $\mathrm{Cl}$ programme than larger companies (Saayman, Pienaar, De Pelsmacker, Viviers, Cuyvers, Muller \& Jegers, 2008). Some of these challenges include lack of training, lack of resources and an inability to provide compelling evidence (Hesford, 2008). Muller (2007) identified and briefly discussed the following $\mathrm{Cl}$ challenges:

Creating a participatory environment and awareness of $\mathrm{Cl}$ : This is a continual challenge. The $\mathrm{Cl}$ Foundation's survey found that most $\mathrm{Cl}$ practitioners created exposure to senior management through the distribution of their 
deliverables. They presented an excellent opportunity for $\mathrm{Cl}$ practitioners to demonstrate the value $\mathrm{Cl}$ provides to the enterprise. As was found in South Africa, although most people in the enterprise knew that $\mathrm{Cl}$ exists but few participated in or contributed to it. Budgetary constraints: It seems to be a global reality for $\mathrm{Cl}$ units, and budgets shrink or grow over time depending on economic factors. Management participation and visibility: This remains a constant challenge, although most respondents reported regular contact with their senior management through their deliverables and many reported high levels of $\mathrm{Cl}$ awareness and increased management visibility. Personnel issues: Finding and retaining the right skills set is another challenge. The outsourcing of research or analysis increased for some of the respondents, while others sourced resources from elsewhere in the enterprise. Showing return on investment/value: Few enterprises measure the return on investment of $\mathrm{Cl}$ and showing value on a constant basis remains a challenge to $\mathrm{Cl}$ units. Identifying critical information needs and the effective and timely gathering of relevant information: Effectiveness includes the optimal use of internal sources of information and knowledge. Training and education in $\mathrm{Cl}$ : This is a global challenge.

Researchers often argue about where to locate Cl (Gilad, 2001). Gilad (2001) argues that many established enterprises traditionally place the $\mathrm{Cl}$ unit under other functions and thereby limit its scope to a narrow functional focus. Ideally, it should sit atop line functions which it should regard as building blocks. According to Hesford (2008), some enterprises consider $\mathrm{Cl}$ to be a high-level function supporting strategic decision making while other enterprises view $\mathrm{Cl}$ as part of market research, supporting the sales and marketing effort. According to Gilad (2001), $\mathrm{Cl}$ is usually located in the following areas:

Independently: is the most realistic reaction to the need to coordinate cross-functional responses to structural changes at the industry level, reporting to the unit president or general manager. Strategy department: The benefits of this include that $\mathrm{Cl}$ people get to deal with strategic issues. Marketing: $\mathrm{Cl}$ that is under a marketing executive's control is too often strictly tracking competitors, focused on tactical information (product, pricing, etc.) and is mostly news reporting. Market research: $\mathrm{Cl}$ is fundamentally different from market research. Market research focuses on the consumer/customer, uses neutral primary research (behavioural or focus groups), employs sophisticated statistical analysis and is heavily biased towards quantitative results (market-share statistics, cluster analysis and multivariate models). Market research is one of many inputs of $\mathrm{Cl}$, since $\mathrm{Cl}$ focuses on the risks in the industry arena and beyond (alternative technologies, substitutes and potential entry). Knowledge management: According to Gilad (2001), placing Cl under knowledge management is a certain kiss of death".

\section{Small and Medium-Sized Enterprises}

SMEs constitute the major part of the productive system in South Africa and without the creation of new SMEs, the country risks economic stagnation (Salles, 2006). Given the failure of the public sector to absorb the growing number of job seekers in South Africa, increasing attention is being focused on entrepreneurship and new enterprise creation, and its potential for contributing to economic growth and job creation Herrington, Kew and Kew (2009). According to Abor and Quartey (2010), SMEs have a crucial role to play in stimulating growth, generating employment and contributing to poverty alleviation, given their economic weight in African countries.

The most widely used framework for SMEs in South Africa is set out in the National Small Business Act 102 of 1996, which defines five categories of businesses in South Africa. The definition is based on the number of employees (the most common definition) per enterprise size combined with the annual turnover categories and the gross assets (excluding fixed property). The two enterprise categories are as follows (Abor \& Quartey, 2010):

Survivalist enterprise: The income generated is less than the minimum income standard or the poverty line. This category is considered pre-entrepreneurial, and includes hawkers, vendors and subsistence farmers. (In practice, survivalist enterprises are often categorised as part of the micro-enterprise sector). Micro enterprise: The turnover is less than the VAT registration limit (that is, R150 000 per year). These enterprises usually lack formality in terms of registration. They include, for example, spaza shops, minibus taxis and household industries. They employ no more than 5 people. Very small enterprise: These are enterprises employing fewer than 10 paid employees, except mining, electricity, manufacturing and construction sectors, in which the figure is 20 employees. These enterprises operate in the formal market and have access to technology. Small enterprise: The upper limit is 50 employees. Small enterprises are generally more established than very small enterprises and exhibit more complex business practices. Medium enterprise: The maximum number of employees is 100 , or 200 for the mining, electricity, manufacturing and construction sectors. These enterprises are often characterised by the decentralisation of power to an additional management layer.

SMEs are considered the backbone of economic growth in all countries. They contribute in providing job opportunities and act as suppliers of goods and services to large enterprises (Singh, Garg \& Deshmukh, 2008). Abor and Quartey (2010) state that the performance of SMEs is important for both the economic development and the social 
development of developing countries. Furthermore, small businesses have been recognised as the engines whereby the growth objectives of developing countries can be achieved (Floyd \& McManus, 2005). They are potential sources of employment and income in many developing countries. In addition, SMEs seem to have advantages over their largescale competitors in that they are able to adapt more easily to market conditions, given their broadly skilled technologies.

Despite the potential role of SMEs to accelerated growth and job creation in developing countries, a number of bottlenecks affect their ability to realise their full potential (Abor \& Quartey, 2010). In addition, Olawale and Garwe (2010) identify the following factors that hinder the progress of SMEs: access to finance; lack of management skills; location and networking; inadequate investment in information technology and cost of production; economic variables and markets; crime and corruption; labour, and infrastructure and regulations. Furthermore, according to Singh et al (2008) SMEs may have the following constraints: scarcity of resources; flat enterprise structure; lack of technical expertise; paucity of innovation; and occurrence of knowledge loss.

\section{Methodology}

A survey was undertaken to collect data from SMEs in the City of Tshwane Metropolitan Municipality (CTMM) of Gauteng Province in South Africa. The CTMM is the largest municipality in South Africa. It is the capital city of South Africa and hosts the Union Buildings. Data was collected from one hundred SMEs from nine locations in the CTMM using a quota sample. A quota sample was undertaken due to time and financial constraints. Locations were sampled in order to cover both urban and rural areas of the CTMM. The sample consisted of $74 \%$ urban and $26 \%$ rural SMEs in the CTMM. The locations included in the sample were Mabobane; Mamelodi; Soshanguve; Ga-Rankuwa; Eersterust; Atteridgeville; Winterveld; Silverton/Pretoria East; Pretoria CBD and Rosslyn. Data were collected using a questionnaire. The data collection process began by contacting SMEs whose contact details were available. SMEs were contacted either by email or by phone. This was done to find out if the SMEs were willing to participate in the survey. For the SMEs that had access to e-mail, the questionnaire was sent to them via e-mail. For the SMEs without e-mail access or any other means of contact; the questionnaires were printed and hand delivered to them. Hand delivered questionnaires were either completed and returned the same day or on an agreed upon date. Since only owners/CEOs/managers were identified as the appropriate candidates to complete the questionnaires, whoever received the questionnaire was asked to forward it to the relevant person. Although some SMEs indicated they were too busy to complete the questionnaire others were very keen to participate in the survey. It was easier to collect data from SMEs in the CBD than those in other locations. SMEs in the CBD are easily accessible and most SMEs in the CBD have access to e-mail. Moreover, travelling costs were cheaper in the CBD.

One hundred and fifty questionnaires were distributed to the respondents hoping that at least one hundred would be returned by the cut-off date. Indeed, one hundred usable questionnaires were received by the cut-off date. E-mail and phone calls were used to follow up on distributed questionnaire. This ensured that the required one hundred questionnaires were returned. Therefore the response rate was $66.67 \%$. The internal data reliability was calculated to be 0.806 (Cronbach' Alpha).

\section{Results}

Of these one hundred SMEs that participated in the survey, only one respondent (1\%) was a sole proprietorship; fourteen respondents (14\%) were partnerships; fifty five (55\%) were close corporation; and thirty (30\%) were companies. Eleven business sectors or subsectors were identified from the literature. Only two additional industries were added by respondents as others and these are: cleaning industry (1\%) and media and marketing (1\%). The remainder of the respondents are spread as follows: Finance and business services (8\%); Catering, accommodation and other trade (19\%); Retail and motor trade and repair services (23\%); Electricity, gas and water (2\%); Community, social and personal services (18\%); Wholesale trade, commercial agents and allied services (5\%); Construction (8\%); and Manufacturing (12\%). Of the one hundred SMEs, fifteen (15\%) had 21 to 50 employees, thirty (30\%) had 11 to 20 employees, thirty six (36\%) had 6 to 10 employees and nineteen (19\%) had 1 to 5 employees. Concerning years of business operation, fifty $(50 \%)$ were operating for 6 or more years, thirty nine (39\%) were operating for 3 to 5 years and only eleven (11\%) were in operation for 1 to 2 years. With regard to annual turnover, two (2\%) SMEs were making a turnover between R6m to R10m, forty eight (48\%) were making a turnover of between R1m and R5m and the rest (50\%) were making less than R1m. Pertaining to owner/manager's educational qualification, five scales were identified, grade 8 to 10, grade 11 to 12 , undergraduate diploma or degree, honours degree and masters or doctoral degree. Only five (5\%) of the respondents had masters or doctoral degree, twenty one (21\%) had honours degree, $47 \%$ had undergraduate diploma or degree and 
twenty seven (27\%) had grade 11 or 12.

To establish SMEs' practice and awareness of $\mathrm{Cl}$, a five-point Likert scale ranging from "Strongly Disagree" to "Strongly Agree" was used. Numbers 1 to 5 we used with number 1 indicating "Strongly Disagree" and number 5 indicating "Strongly Agree". Table 2 shows the different variables used to establish the awareness and practice of $\mathrm{Cl}$ by SMEs. The aim of variable 1 was to establish whether the respondents were aware of $\mathrm{Cl}$. The mean was calculated as 4.12 and the standard deviation was 0.671 . The lower standard deviation indicates that there was less spread of responses to this question. The mean of 4.12 indicates that nearly all of the respondents indicated that they were aware of $\mathrm{Cl}$. Variable 2 was intended to determine whether the respondents practiced $\mathrm{Cl}$ in their businesses. The standard deviation of 0.687 reveals that there was less spread of responses to the question. Moreover, it indicates that more respondents concurred with the mean of 4.45 . The mean reveals that the majority of the respondents agreed that they practice $\mathrm{Cl}$ in their enterprises. Variable 3 was designed to determine whether the respondents had a formalised $\mathrm{Cl}$ function. The higher standard deviation of 1.143 indicates that there was more spread of responses to this variable. Also, it points out that fewer respondents concurred with the mean. The mean of 2.16 indicates that most of the respondents disagreed with the statement. This means that most of the respondents did not have a formalised $\mathrm{Cl}$ function. The reason behind variable 4 was to ascertain whether the respondents had a formalised $\mathrm{Cl}$ process. The slightly higher standard deviation of 1.078 indicates that there was more spread of responses to this question. Moreover, it reveals that fewer respondents concurred with the mean. The mean of 2.01 indicates that most of the respondents disagreed with the statement, which means that they did not have a formalised $\mathrm{Cl}$ process. The purpose of variable 5 was to ascertain whether the respondents hired people or other businesses to collect information on their behalf. The mean and standard deviation were 3.10 and 1.202 respectively. The high standard deviation indicates that there was more spread of responses to this question. The mean of 3.10 signifies that more respondents hired people or other businesses to collect information on their behalf. Variable 6 was intended to establish whether the respondents had a computerised $\mathrm{Cl}$ system. The high standard deviation of 2.436 indicates that there was more spread of responses to this variable. The mean of 1.84 indicates that more respondents strongly disagreed with the statement. This means that most of the respondents did not have a computerised $\mathrm{Cl}$ system.

Table 1: Competitive Intelligence awareness and practice variables

\begin{tabular}{|c|l|c|c|}
\hline Variable number & Variables for establishment of $\mathbf{C l}$ awareness and practice & Mean & Standard deviation \\
\hline 1 & We are aware of competitive intelligence. & 4.12 & 0.671 \\
\hline 2 & We practice competitive intelligence in our business. & 4.45 & 0.687 \\
\hline 3 & Our business has a formalised competitive intelligence function. & 2.16 & 1.143 \\
\hline 4 & We have a formalised competitive intelligence process. & 2.01 & 1.078 \\
\hline 5 & We hire people or other businesses to collect information on our behalf. & 3.10 & 1.202 \\
\hline 6 & We have a computerised competitive intelligence system. & 1.84 & 2.436 \\
\hline
\end{tabular}

The $\mathrm{Cl}$ locations identified by Gilad (2001) were used to establish the location of $\mathrm{Cl}$ in SMEs. Table 2 indicate that (43\%) of these SMEs indicated that their $\mathrm{Cl}$ was located independently. The rest of the SMEs' $\mathrm{Cl}$ was spread as follows: market research (29\%); marketing department (25\%); knowledge management (1\%); strategy management department (1\%); and public relations (1\%). It is clear therefore that the majority of these SMEs locate their $\mathrm{Cl}$ independently.

Table 2: Location of competitive Intelligence

\begin{tabular}{|l|c|}
\hline Competitive intelligence locations & Number of respondents \\
\hline Independence department & 43 \\
\hline Market research (MR) & 29 \\
\hline Marketing department & 25 \\
\hline Knowledge management & 1 \\
\hline Strategy management department & 1 \\
\hline Public relations & 1 \\
\hline
\end{tabular}

\section{Discussion}

The majority of the SMEs were close corporations. Perhaps this is because registration of close corporation was cheaper 
than that of a company. Also, close corporations are formally structured than partnerships and sole proprietorship. The majority of the SMEs were operating in the retail and motor trade and repair services. The majority of the SMEs had six to ten employees. This indicates that most of the SMEs were very small.

The majority of these SMEs had been operating for more than six years. This means that these SMEs had many years of business experience. These SMEs were therefore exposed to different business scenarios. The majority of these SMEs were making a turnover of less than one million rand. This means that they did not have a bargaining power. This coincide with current literature that SMEs lack funds. As a result, SMEs find it difficult to compete with larger enterprises. The majority of the owners/manager had an undergraduate diploma or degree. They had a reasonable education background. This could be the reason why majority of these SMEs has been in operation for more than six years.

The findings reveal that the majority of these SMEs were aware of $\mathrm{Cl}$. This means that during their years of operation, they realise that $\mathrm{Cl}$ exist. The majority of these SMEs also indicated that they practice $\mathrm{Cl}$. This means that they plan, collect, process, analyse and disseminate actionable intelligence. However, the majority of these SMEs indicated that they practice $\mathrm{Cl}$ informally. Perhaps this is because SMEs lack resources. Surprisingly, the majority of these SMEs hire people or other enterprises to conduct $\mathrm{Cl}$ on their behalf. This means that they outsource their $\mathrm{Cl}$ to people or enterprises. It was beyond this research to establish the extent to which these SMEs outsource $\mathrm{Cl}$ and the scale of $\mathrm{Cl}$ outsourcing investment.

The findings reveal that the majority of these SMEs locate their $\mathrm{Cl}$ independently. Perhaps this is because most SMEs are not formally structure. Also, SMEs lack resources to have all the functions that larger enterprises have. A larger number of these SMEs indicated that their $\mathrm{Cl}$ is located either in market research or marketing department. Because marketing research is a responsibility of the marketing department, majority of these SMEs locate their $\mathrm{Cl}$ in the marketing department. This concur with the current literature that most enterprises locate their $\mathrm{Cl}$ in the marketing department. This has led some researcher to call $\mathrm{Cl}$ as marketing intelligence.

\section{Conclusion}

The majority of these SMEs are aware of $\mathrm{Cl}$. Although they do so informally, these SMEs practice $\mathrm{Cl}$. This is because most of these SMEs are very small and lack resources to formalise their $\mathrm{Cl}$. Realising their lack of relevant skills, the majority of these SMEs outsource $\mathrm{Cl}$ to people or other enterprises. The majority of these SMEs has been in operation long enough to realise the importance of $\mathrm{Cl}$. Also, the majority of these SMEs are led by people who have reasonable educational qualifications. However, the annual turnover of the majority of these SMEs was less than one million rand. This meant that they had less to invest on $\mathrm{Cl}$ implementation and formalisation.

The purpose of this research was to establish the location of $\mathrm{Cl}$ in SMEs. The research established that the majority of these SMEs locate their $\mathrm{Cl}$ in the marketing department. This is because most of these SMEs indicated that their $\mathrm{Cl}$ is located either in marketing research or marketing department. Marketing research is a responsibility of the marketing department. Therefore, SMEs locate their $\mathrm{Cl}$ in the same function as larger enterprises. However, almost half of these SMEs located their $\mathrm{Cl}$ independently. This is because most SMEs do not have formal structures and lack resources. While some researchers suggest that $\mathrm{Cl}$ must be located in a strategic function, there is a continual trend of locating $\mathrm{Cl}$ in the marketing department. Therefore, future research must be conducted to establish why majority of enterprises locate $\mathrm{Cl}$ in the marketing department.

\section{Acknowledgements}

This work is based on the research supported by the National Research Foundation. The authors would also like to acknowledge the University of South Africa (South Africa) for the funding and support without which this research would not have been possible.

\section{References}

Abor, J. \& Quartey, P. (2010). Issues in SME development in Ghana and South Africa. International Research Journal of Finance and Economics, 1(39), 218-228.

Adidam, T.J., Gajre, S. \& Kejriwal, S. (2009). Cross-cultural competitive intelligence strategies. Marketing Intelligence \& Planning, 27(5), $666-680$.

Adidam, P.T., Banerjee, M. \& Shukla, P. (2012). Competitive intelligence and firm's performance in emerging markets: an exploratory study in India. Journal of Business \& Industrial Marketing, 27(3), $242-254$. 
Bartes, F. (2012). Increasing the competitiveness of company by competitive intelligence. 7th International Scientific Conference "Business and Management, May 10-11, 2012, Vilnius, LITHUANIA, 808-814.

Bernstein, J.H. (2011). The Data Information Knowledge Wisdom Hierarchy and its Antithesis. https://journals.lib.washington.edu/index.p hp/nasko/article/viewFile/12806/11288 (accessed 14 May 2012)

Bose, R. (2008). Competitive intelligence process and tools for intelligence analysis. Industrial Management \& Data Systems, 108(4), $510-528$.

Bourret, C. (2012). Standards, evaluation, certification and implications for the study of competitive intelligence. Journal of Intelligence Studies in Business, 2(1), 59-67.

Breese-Vitelli, J. (2011). A comparative analysis of the use of competitive intelligence tools in a multinational corporation. DSc thesis, Robert Morris University, Chicago.

Brody, R. (2008). Issues in defining competitive intelligence: An exploration. Journal of Competitive Intelligence and Management, 4(3); 3-16.

Buchda, S. (2007). Rulers for business intelligence and competitive intelligence: An overview and evaluation of measurement approaches. Journal of Competitive Intelligence and Management, 4(2); 23-54.

Deng, Z. \& Luo, L. (2010). An exploratory discussion of new ways for competitive intelligence on Web2.0. International Federation for Information Processing, 252(1); 597-604.

Dishman, P.L. \& Calof, J.L. (2008). Competitive intelligence: A multiphasic precedent to marketing strategy. European Journal of Marketing, 42(7/8); 766-785.

Fleisher, C.S. \& Wright, S. (2009). Examining differences in competitive intelligence practice: China, Japan, and the West. Thunderbird International Business Review, 51(3); 249-261.

Floyd, D. \& McManus, J. (2005). The role of SMEs in improving the competitive position of the European Union. European Business Review, 17(2); 144-150.

Frion, P. \& Yzquierdo-Hombrecher, J. (2009). How to implement competitive intelligence in SMEs? Paper presented at Visio 2009, Vitoria-Gasteiz, Spain, 4\&5 June.

Gilad, B. (2001). Industry risk management: Cl's next step. Competitive Intelligence Magazine, 4(3), $21-27$.

Guarda, T., Augusto, M. \& Silva, C. (2012). Competitive advantage in e-commerce: the case of database marketing. Advances in Intelligent and Soft Computing, 143(1), 123-130.

Heppes, D. \& Du Toit, A. (2009). Level of maturity of the competitive intelligence function: Case study of a retail bank in South Africa. Aslib Proceedings: New Information Perspectives, 61(1), 48-66.

Herrington, M., Kew, J. \& Kew, P. (2009). Global Entrepreneurship Monitor, South African report. http://www.gbs.nct.ac.za/gbswebb/ userfiles/gemsouthafrica2000pdf (accessed on 15 October 2011).

Hesford, J.W. (2008). An empirical investigation of accounting information use in competitive intelligence. Journal of Competitive Intelligence and Management, 4(3), 17-49.

Hughes, S. (2005). Competitive intelligence as competitive advantage. Journal of Competitive Intelligence and Management, 3(3), 3-18.

Johns, P. \& Van Doren, D.C. (2010). Competitive intelligence in service marketing: A new approach with practical application. Marketing Intelligence \& Planning, 28(5), 551-570.

Juhari, A.S. \& Stephens, D. (2006). Tracing the origins of competitive intelligence through history. Journal of Competitive Intelligence and Management, 3(4), 61-82.

Koseoglu, M.A., Karayormuk, K., Parnell, J.A. \& Menefee, M.L. (2011). Competitive intelligence: Evidence from Turkish SMEs. International Journal of Entrepreneurship and Small Business, 13(3), 333-349.

Muller, M.L. (2007). Global competitive intelligence practice. South African Journal of Information Management, 9(3).

Muller, M.L. (2005a). Beyond competitive intelligence-innovation and competitive strategy. South African Journal of Information Management, 7(1).

Muller, M.L. (2005b). Competitive intelligence in South Africa: Status quo in 2005. South African Journal of Information Management, $7(4)$.

Murphy, C. (2006). Competitive intelligence: What corporate documents can tell you. Business Information Review, 23(35), 35-42.

Nasri, W. (2011). Competitive intelligence in Tunisian companies. Journal of Enterprise Information Management, 24(1), 53-67.

Olawale, F. \& Garwe, D. (2010). Obstacles to the growth of new SMEs in South Africa: A principal component analysis approach. African Journal of Business Management, 4(5), 729-738.

Onifade, O.F.W., Thiery, O., Osofisan, A.O. \& Duffing, G. (2013). Study of Risk Factors in Competitive Intelligence Decision Making: A Cognitive Approach. Competitive Intelligence and Decision Problems, 93-111.

Patterson, L. \& Martzoukou, K. (2012). An examination of Canadian information professionals' involvement in the provision of business information synthesis and analysis services. Journal of Librarianship and Information Science, 44(1), 47 - 64.

Pearce, J.A. \& Robinson, R.B. (2005). Strategic management: Formulation, implementation and control. 9th edition. Carolina: McGrawHill.

Pietersen, M.A. (2006). Competitive intelligence at the Medical Research Council. Master's dissertation, University of Stellenbosch, Stellenbosch.

Peltoniemi, M. \& Vuori, E. (2008). Competitive intelligence as a driver of co-evolution within an enterprise population. Journal of Competitive Intelligence and Management, 4(3), $50-62$.

Post, G.V. \& Anderson, D.L. (2003). Management Information Systems: Solving Business Problems with Information Technology. 
3rdedition. Boston: McGraw-Hill//rwin.

Qiu, T. (2008). Scanning for competitive intelligence: A managerial perspective. European Journal of Marketing, 42(7/8), 814 - 835.

Raynor, M.E. (2007). The Strategy Paradox: why committing to success leads to failure and what to do about it. New York: Currency Doubleday Press.

Rittenburg, T.L., Valentine, S.R. \& Faircloth, J.B. (2007). An ethical decision-making framework for competitive intelligence gathering. Journal of Business Ethics, 70(1), 235-245.

Saayman, A., Pienaar, J., De Pelsmacker, P., Viviers, W., Cuyvers, L., Muller, M.L. \& Jegers, M. (2008). Competitive intelligence: Construct exploration, validation and equivalence. Aslib Proceedings: New Information Perspectives, 60(4), 383-411.

Salles, M. (2006). Decision making in SMEs and information requirements for competitive intelligence. Production Planning \& Control, 17(3), 229-237.

Santos, M. \& Correia, A. (2010). Competitive intelligence as a source of competitive advantage: An exploratory study of the Portuguese biotechnology industry. Paper presented at the $11^{\text {th }}$ European Conference on Knowledge Management, 2\&3 September.

Sauter, V.L. \& Free, D. (2005). Competitive intelligence systems: Qualitative DSS for strategic decision making. The Database for Advances in Information Systems, 36(2), 43-57.

Shih, M.J., Liu, D.R. \& Hsu, M.L. (2008). Mining changes in patent trends for competitive intelligence. Advances in Knowledge Discovery and Data Mining, 5012(1), 999-1005.

Shih, M., Liu, D.R. \& Hsu, M. (2010). Discovering competitive intelligence by mining changes in patent trends. Expert Systems with Application, 37(4), 2882-2890.

Simon, H. (1977). Review of the new science of management decision. Administrative Science Quarterly, 1(1), 342-351.

Singh, R.K., Garg, S.K. \& Deshmukh, S.G. (2008). Strategy development by SMEs for competitiveness: A review. Benchmarking: An International Journal, 15(5), 525-547.

Smith, J.R., Wright, S. \& Pickton, D. (2010). Competitive intelligence programmes for SMEs in France: Evidence of changing attitudes. Journal of Strategic Marketing, 18(7), 523 - 536.

Stair, R. \& Reynolds, G. (2006). Principles of information systems. USA: Thompson Course Technology.

Ponis, S.T. \& Christou, L.T. (2013). Competitive intelligence for SMEs: a web-based decision support system. International Journal of Business Information Systems, 12(3), 243-258.

Strauss, A.C. \& Du Toit, A.S.A. (2010). Competitive intelligence skills needed to enhance South Africa's competitiveness. Aslib Proceedings: New Information Perspective, 62(3), 302-320.

Taleghani, M., Rad, S.K. \& Rahmati, Y. (2012). The Role of Innovation in the Relationship between Knowledge Management and Competitive Advantage (An Empirical Study of Tourism Industry). Journal of Basic and Applied Scientific Research, 2(4), 36073614.

Tanev, S. \& Bailetti, T. (2008). Competitive intelligence information and innovation in small Canadian firms. European Journal of Marketing, 42(7/8), 786-803.

Tarraf, T. \& Molz, R. (2006). Competitive intelligence at small enterprises. SAM Advanced Management Journal, 71(4), 24-34.

Thompson, J. \& Martin, F. (2005). Strategic management: Awareness and change. Hampshire: Cengage Learning.

Trim, P.R.J. \& Lee, Y. (2007). A strategic marketing intelligence and multi- organisational resilience framework. European Journal of Marketing, 42(7/8), 731-745.

Wright, W. (2005). The CI marketing interface. Journal of Competitive Intelligence and Management, 3(2), 3-7.

Xinping, S., Cuijuan, L. \& Youfa, W. (2011). Competitive intelligence service for SMEs: A new way for B2B Website to compete. Paper presented at the International Conference on Management and Service Science (MASS), 12-14 August.

Zha, X. \& Chen, M. (2009). Competitive intelligence monitoring in the risk prevention of SMEs. Journal of Service Science \& Management, 3(1), 230-235. 